\title{
Meningeal metastasis patients with EGFR G724S who develop resistance to osimertinib benefit from the addition of afatinib
}

\author{
Yibin Li", Yantang Lin", Jingxun Wu, Feng Ye \\ Department of Medical Oncology, The First Affiliated Hospital of Xiamen University, Xiamen, China \\ \#These authors contributed equally to this work. \\ Correspondence to: Jingxun Wu; Feng Ye, MD. Department of Medical Oncology, Xiamen Key Laboratory of Antitumor Drug Transformation \\ Research, The First Affiliated Hospital of Xiamen University, Xiamen, China. Email: Wujingxun@xmu.edu.cn; yefengdoctor@xmu.edu.cn.
}

Submitted Jun 23, 2020. Accepted for publication Aug 21, 2020.

doi: $10.21037 /$ tlcr-20-847

View this article at: http://dx.doi.org/10.21037/tlcr-20-847

A case study of a patient with EGFR G724S who responded to afatinib monotherapy after disease progression on osimertinib was reported before (1). Incidentally, we encountered a patient who also had EGFR G724S who developed meningeal metastases. After treatment with a regimen of osimertinib combined with afatinib, our patient achieved significant clinical benefits.

A 49-year-old Chinese male smoker was found to have a pulmonary mass in the right middle lobe by chest computed tomography (CT) scan during a health checkup on October 25, 2016. The patient underwent positron emission tomography-computed tomography (PET-CT) on November 01, 2016 (Figure 1A), which showed irregular soft tissue nodules in the right middle lobe (measuring approximately $2.1 \mathrm{~cm} \times 2.4 \mathrm{~cm}$ ), lymph node metastasis in the right hilar and mediastinum (3A, 4R, 10R, and 7 areas), and multiple bone metastases. On November 07, 2016, the patient underwent thoracoscopy lung wedge resection and pleural biopsy. During the operation, extensive pleural cavity implantation and metastases were observed. Postoperative pathology and next-generation sequencing (NGS) led to the diagnosis of lung adenocarcinoma with an EGFR exon 19 deletion mutation (EGFR 19del). Subsequently, the patient started gefitinib $250 \mathrm{mg}$ daily as first-line therapy on November 25, 2016, and achieved partial response (PR). On December 14, 2017, craniocerebral magnetic resonance imaging (MRI) showed multiple progressive small metastases in the brain (Figure 1B). Consequently, the patient's regimen was changed to osimertinib $80 \mathrm{mg}$ daily from December 15, 2017.
On November 19, 2018, the patient experienced an increase in pleural effusion as disease progression. An NGS test of the patient's pleural effusion revealed the emergence of EGFR G724S with pre-existing EGFR 19del. Thereafter, while maintaining the use of osimertinib, the patient received chemotherapy including carboplatin and pemetrexed, with bevacizumab as an antiangiogenic therapy.

After experiencing dizziness and headache, the patient was reexamined by craniocerebral MRI on August 05, 2019, which revealed extensive abnormal thickening and enhancement of the meninges; meningeal metastases were considered. CT at the same time showed multiple liver metastases and peritoneal metastases.

Another NGS examination of the patient's pleural effusion and blood was performed, which showed EGFR G724S and 19del mutation were still present in both samples. Considering both in vitro and in vivo studies have indicated that EGFR G724S/19del can induce resistance to osimertinib in patients while maintaining sensitivity to afatinib $(2,3)$, the patient began afatinib $40 \mathrm{mg}$ daily while continuing osimertinib $80 \mathrm{mg}$ daily on August 06, 2019. After 1 month, the patient's neurological symptoms were significantly relieved, and after 2 months, follow-up CT and MRI showed that the patient's meningeal metastases, liver metastases and peritoneal metastases were significantly reduced (Figure 1C,D). To date (March 26, 2020, the cutoff day), the patient has continued to receive afatinib in combination with osimertinib, and no obvious adverse reactions have been observed (Figure 1E). All procedures performed in studies involving human participants were in 
A

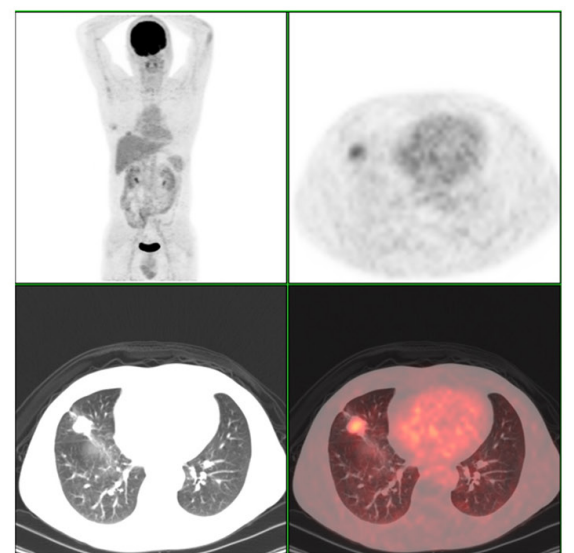

B

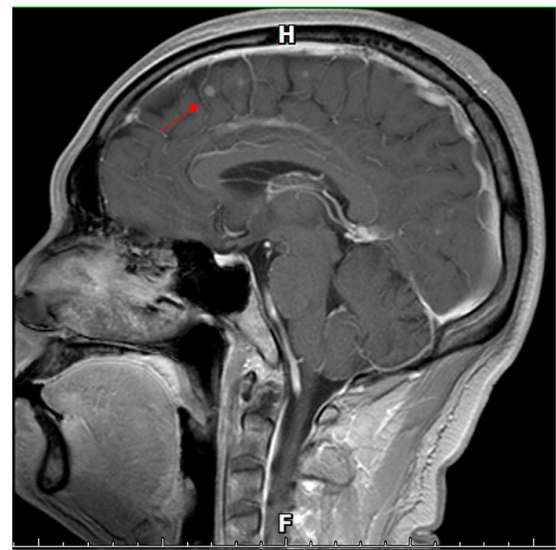

C November 19, 2018
Osimertinib + Chemotherapy base line

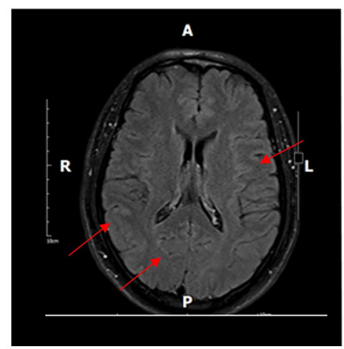

D
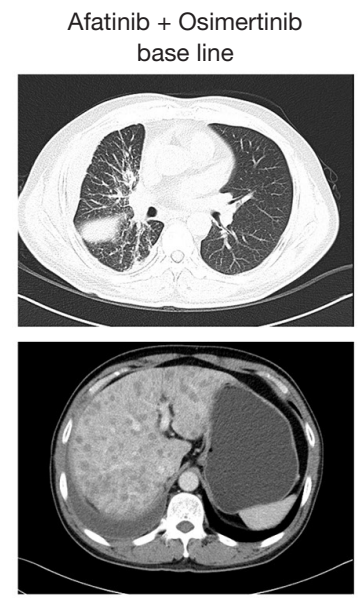

E

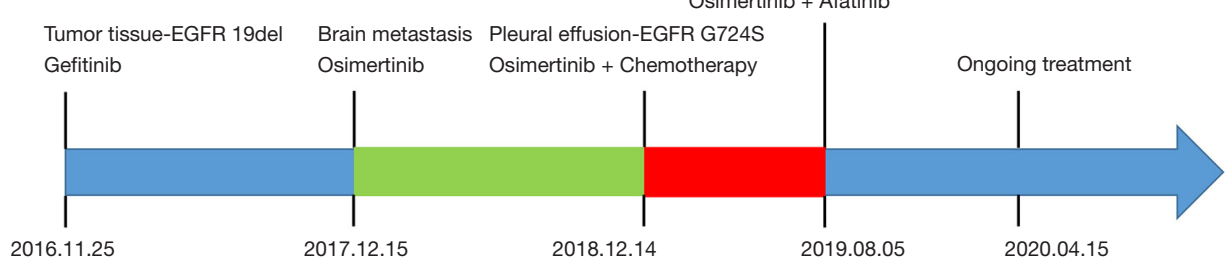

August 05, 2019

Afatinib + Osimertinib base line

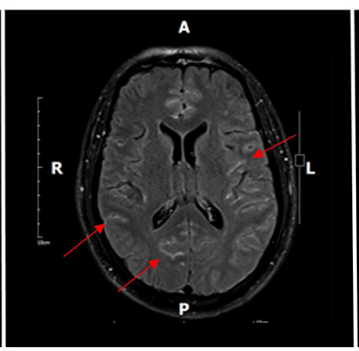

Lung lesions SD, Liver lesions PR
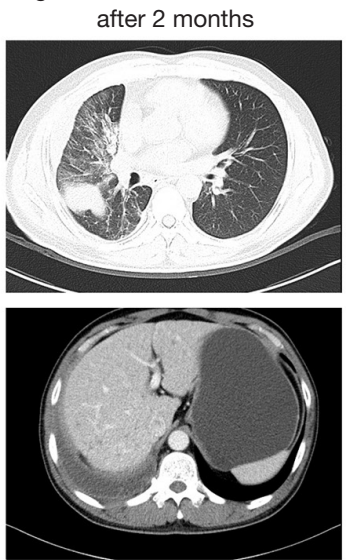

Liver and meningeal metastasis

pleural effusion and blood-EGFR G724S
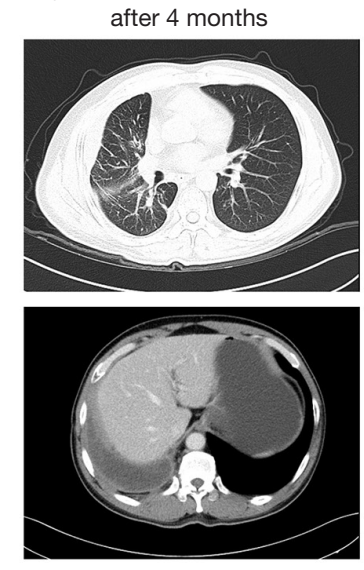

er 08, 2019

after 4 months

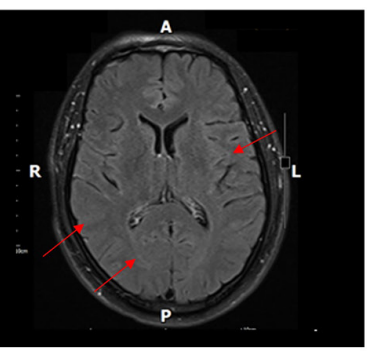

Lung lesions PR, Liver lesions PR

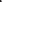


accordance with the ethical standards of the institutional and/or national research committee(s) and with the Helsinki Declaration (as revised in 2013). Written informed consent was obtained from the patient.

In the previous case report, the patient treated with osimertinib combined with afatinib experienced rapid disease progression (4). However, in this case, a patient with EGFR G724S with meningeal metastases who has achieved significant clinical benefit from the combination therapy regimen is reported for the first time. The patient has achieved progression-free survival of more than 8 months, and the neurological symptoms caused by meningeal metastases have significantly improved.

In summary, this case demonstrates that a regimen of osimertinib combined with afatinib can achieve significant effects in patients with EGFR G724S mutation after progression on osimertinib, especially in those who have meningeal metastases. This represents a new treatment strategy for such patients.

\section{Acknowledgments}

Funding: Supported by National Major Scientific and Technological Special Project for "Significant New Drugs Development” (2020ZX09201005).

\section{Footnote}

Provenance and Peer Review: This article was a free submission. The article has undergone external peer review.

Conflicts of Interest: All authors have completed the ICMJE uniform disclosure form (available at http://dx.doi. org/10.21037/tlcr-20-847). The authors have no conflicts of interest to declare.

Ethical Statement: The authors are accountable for all aspects of the work in ensuring that questions related to the accuracy or integrity of any part of the work are appropriately investigated and resolved. All procedures performed in studies involving human participants were in accordance with the ethical standards of the institutional and/or national research committee(s) and with the Helsinki Declaration (as revised in 2013). Written informed consent was obtained from the patient.

Open Access Statement: This is an Open Access article distributed in accordance with the Creative Commons Attribution-NonCommercial-NoDerivs 4.0 International License (CC BY-NC-ND 4.0), which permits the noncommercial replication and distribution of the article with the strict proviso that no changes or edits are made and the original work is properly cited (including links to both the formal publication through the relevant DOI and the license). See: https://creativecommons.org/licenses/by-nc-nd/4.0/.

\section{References}

1. Fang W, Huang Y, Gan J, et al. Emergence of EGFR G724S After Progression on Osimertinib Responded to Afatinib Monotherapy. J Thorac Oncol 2020;15:e36-e37.

2. Fassunke J, Müller F, Keul M, et al. Overcoming EGFRG724S-mediated osimertinib resistance through unique binding characteristics of second-generation EGFR inhibitors. Nat Commun 2018;9:4655.

3. Brown BP, Zhang YK, Westover D, et al. On-target Resistance to the Mutant-Selective EGFR Inhibitor Osimertinib Can Develop in an Allele-Specific Manner Dependent on the Original EGFR-Activating Mutation. Clin Cancer Res 2019;25:3341-51.

4. Peled N, Roisman LC, Miron B, et al. Subclonal Therapy by Two EGFR TKIs Guided by Sequential Plasma Cellfree DNA in EGFR-Mutated Lung Cancer. J Thorac Oncol 2017;12:e81-e84.

(English Language Editor: J. Reynolds)
Cite this article as: $\mathrm{Li} \mathrm{Y}$, Lin $\mathrm{Y}, \mathrm{Wu} \mathrm{J}$, Ye F. Meningeal metastasis patients with EGFR G724S who develop resistance to osimertinib benefit from the addition of afatinib. Transl Lung Cancer Res 2020;9(5):2188-2190. doi: 10.21037/tlcr-20-847 